\title{
SOLID BREAST NEOPLASMS: DIFFERENTIAL DIAGNOSIS WITH PULSED DOPPLER ULTRASOUND
}

\author{
T. J. A. Kuijpers, A. I. M. Obdeijn, R. H. Kruyt and M. Oudkerk \\ Department of Radiology, Dr. Daniel den Hoed Cancer Center, Groene Hilledijk 301,
} 3075 EA Rotterdam, The Netherlands

(Received 20 September 1993; in final form 17 January 1994)

\begin{abstract}
In this prospective study, duplex Doppler ultrasound was used in 95 consecutive patients with solid breast masses to evaluate the presence of neovascular flow. A positive Doppler signal, i.e., a Doppler shift frequency of more than $1 \mathrm{kHz}$ using a $5 \mathrm{MHz}$ insonating frequency, was found in 34 of 57 patients with a carcinoma, and also in three patients with a benign condition. These results indicate that negative findings with pulsed Doppler ultrasound cannot be used to exclude malignancy. However, a frequency shift of more than $1 \mathrm{kHz}$ indicates a high probability for malignancy. In our study a high frequency shift was not related to tumor size. We also evaluated the correlation between a high frequency shift and axillary nodal metastasis. According to our results there is a very low chance of axillary metastasis when no high frequency shifts are found.
\end{abstract}

Key Words: Ultrasound, Doppler, Tissue characterization, Neoplasms, Blood supply, Breast neoplasms.

\section{INTRODUCTION}

Ultrasonography has an established role in the evaluation of palpable breast masses in the differentiation of cystic from solid masses and in the evaluation of nonpalpable lesions seen on a mammogram. Although there are sonographic criteria for malignancy and benignancy, there is a sizable percentage of false negative and false positive results (Cole-Beuglet et al. 1983). Therefore, in all solid masses malignancy cannot be excluded or proven by ultrasonic imaging.

It is known that initial tumor growth and metastasis is correlated with neovascularization (Burns et al. 1982; Folkman and Hanahan 1991; Schoenberger et al. 1988; Taylor 1987; Taylor et al. 1988; Taylor and Holland 1990; Weidner et al. 1992). The frequent occurrence of arteriovenous anastomoses, but also the relative lack of muscle in the wall of these (abnormally wide) vessels in tumor vascularization, gives rise to changes in vessel impedance and very high flow velocities, which is unlikely in normal vessels with small diameters $(<1.5 \mathrm{~mm})$ because of the blood viscosity. With duplex Doppler, tumor perfusion can be evaluated (Kuijpers and Jaspers 1989; Ramos et al. 1988; Taylor et al. 1987).

Duplex Doppler combines the ultrasound real time

Address correspondence to: T. J. A. Kuijpers. image with pulsed Doppler information. The perfusion characteristics can be seen on a B-scan image. The frequency of the tumor signal is determined by the velocity of the red blood cells and related to the frequency of the transducer, and depends on the angle between the flow and beam directions.

The aim of our prospective study was to evaluate the use of pulsed Doppler ultrasound in tissue characterization of solid breast masses. We also studied the correlation of a high frequency shift and pathological lymph nodes and the correlation of a high frequency shift and tumor size.

\section{MATERIALS AND METHODS}

Over a 14-month period we performed an ultrasound examination in all patients with a palpable breast mass and/or lesion on mammography. Patients with microcalcifications were excluded from the study. Also, when the mass appeared to be a cyst, the patients were excluded. When a solid mass was identified with ultrasound we performed a pulsed Doppler analysis.

We examined 95 consecutive patients with a solid lesion referred for biopsy, ranging in age from 21 to 96 years, with pulsed Doppler ultrasound. The mirror image of the other breast served as a control.

The UGR 34-35D 280 LS Doppler unit (Aloka, Tokyo) was used to perform these examinations. The 
Table 1. Histology and frequency shift of the benign, false positive lesions.

\begin{tabular}{cllc}
\hline Number & Histology & Frequency shift & Age \\
\hline 1 & mastopathy & $2.10 \mathrm{kHz} / 0.60(\mathrm{~S} / \mathrm{D})$ & 50 years \\
2 & mastopathy & $1.00 \mathrm{kHz} / 0.30(\mathrm{~S} / \mathrm{D})$ & 54 years \\
3 & mastitis & $1.00 \mathrm{kHz} / 0.30(\mathrm{~S} / \mathrm{D})$ & 75 years \\
\hline
\end{tabular}

spatial peak-temporal average intensity in the focus area was $760 \mathrm{~mW} / \mathrm{cm}^{2}$. The high frequency Aloka unit operates at an insonating frequency of $5 \mathrm{MHz}$. The unit incorporates a real-time scanner and a range-gated Doppler velocity meter.

At the onset of each Doppler study the wall filter was set as low as possible $(100 \mathrm{~Hz})$. The real-time Bmode was used to locate the tumor. A pulse repetition frequency of $4.2 \mathrm{kHz}$ was available to detect slow blood flow $(30 \mathrm{~cm} / \mathrm{s}$ at $5 \mathrm{MHz}$ insonating frequency). When the lesion was located, the Doppler cursor was placed at the periphery of the mass. A sample window of 4-5 mm was used to search for Doppler shifts. When a signal was detected, the sample window was reduced to 2-3 $\mathrm{mm}$, and the transducer was repositioned so that the line of sight was more parallel to the direction of the blood flow; this resulted in a higher frequency shift. Normal flow in breast parenchyma is usually of low velocity, giving Doppler shift signals of $200-500 \mathrm{~Hz}$. A Doppler frequency shift of more than $1 \mathrm{kHz}$ was defined as a positive Doppler signal.

Because the tumor vessels are small and the accurate course cannot be seen on an echo image, the angle between ultrasound beam and flow direction is unknown. Because of the inaccuracies in determining the angle of insonation, it was chosen to provide Doppler shift rather than angle corrected flow velocities.

In every patient the tumor size was measured by ultrasound imaging. Histologic confirmation was achieved in all patients. In case of a carcinoma the presence of positive lymph nodes was recorded. The entire examination usually took $10 \mathrm{~min}$. Informed consent was obtained from each patient.

\section{RESULTS}

We found a positive Doppler signal in 37 patients of whom 34 proved to have a malignancy. In the three other patients with positive findings, the histologic specimens were evaluated as mastopathy and mastitis (see Table 1).

In the remaining 58 patients no Doppler signal or a frequency shift of less than $1 \mathrm{kHz}$ was found. Twenty-three of them proved to be carcinoma of the breast, while 35 lesions were benign. These results are listed in Table 2. An example of a malignant tumor with a positive Doppler signal and of a benign lesion without Doppler signal is visible in Fig. 1.

In 34 of 57 patients with a high frequency shift, the mean diameter of the tumor was $2.4 \mathrm{~cm}$. In the other 23 without a positive Doppler signal, the mean diameter was $2.1 \mathrm{~cm}$. In 53 of 57 patients with a carcinoma there was information about the axillary lymph nodes. In 15 patients with a positive Doppler signal there was no axillary nodal metastasis, while 16 patients had positive nodes. In 19 of the Doppler negative patients there was no axillary nodal metastasis, while only three of the Doppler negative patients had positive nodes. This information is listed in Table 3.

\section{DISCUSSION}

Over the years, substantial efforts have been made to find a noninvasive way of tissue characterization, with only modest results. Detection of vascular signals in tumors with Doppler ultrasound may be useful for tissue characterization. Because of the characteristics of tumor vascularization, which results in alterations of the blood flow velocity, a high frequency shift can be observed with pulsed Doppler ultrasound.

According to the literature, a high frequency shift can be found not only in breast carcinomas but in benign breast lesions as well. In addition, not all carcinomas are associated with a high Doppler shift frequency (Bohm-Velez and Mendelson 1989; Burns et al. 1982; Dock et al. 1991). In our study a high frequency shift was found in $60 \%$ of the malignancies, but also in three benign conditions, meaning a specificity of $92 \%$. These results are in the same range as those of the large study of Burns et al. (1982). They investigated 55 breast carcinomas and 349 benign lesions and found a sensitivity of $73 \%$ and a false positive rate of only $1 \%$. Dock et al. (1991) had similar results. In a study population of 44 patients with breast masses, they found a sensitivity of $65 \%$ and specificity of $85 \%$.

Only Schoenberger et al. (1988) had a different outcome. In a group of 38 patients, all 12 patients with

Table 2. Correlation between duplex ultrasound and histology.

\begin{tabular}{lcc}
\hline & \multicolumn{2}{c}{ Histologic diagnosis } \\
\cline { 2 - 3 } Duplex ultrasound & Benign & Malignant \\
\hline $\begin{array}{l}\text { Solid mass with high frequency shift } \\
\text { of } \geqslant 1 \mathrm{kHz}\end{array}$ & 3 & 34 \\
$\begin{array}{l}\text { Solid mass with no frequency shift } \\
\text { or }<1 \mathrm{kHz}\end{array}$ & 35 & 23 \\
\hline
\end{tabular}




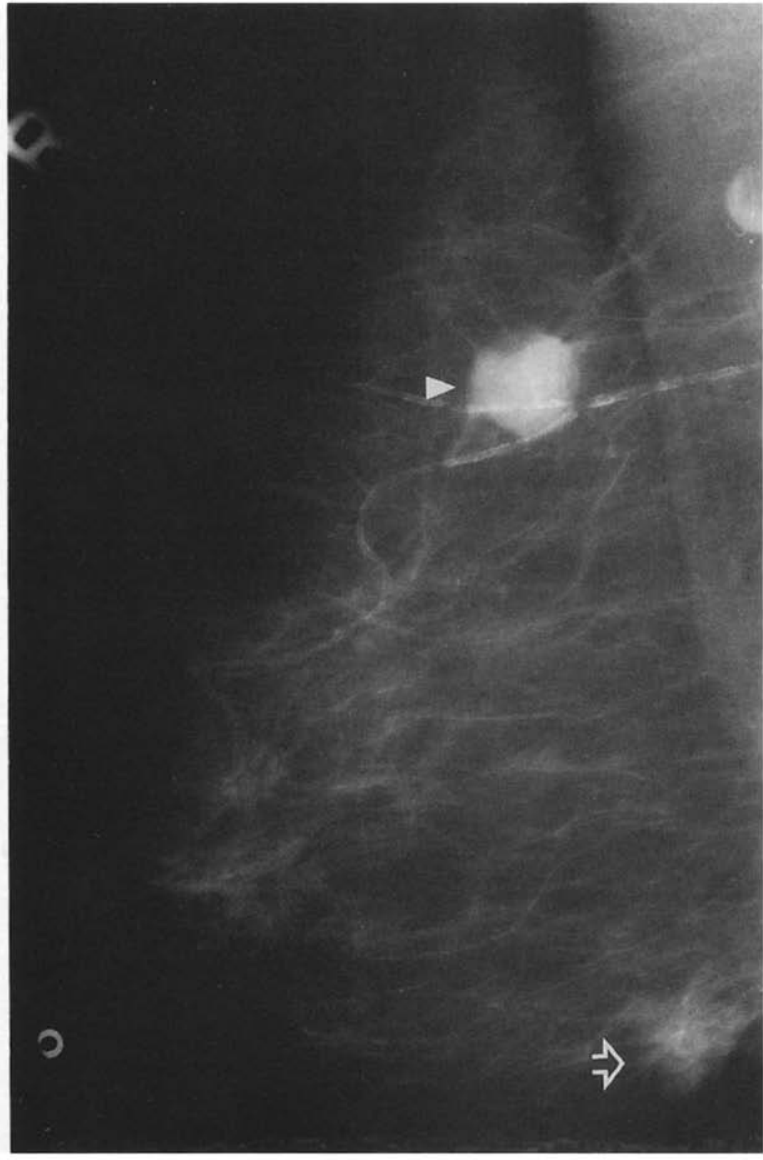

(a)

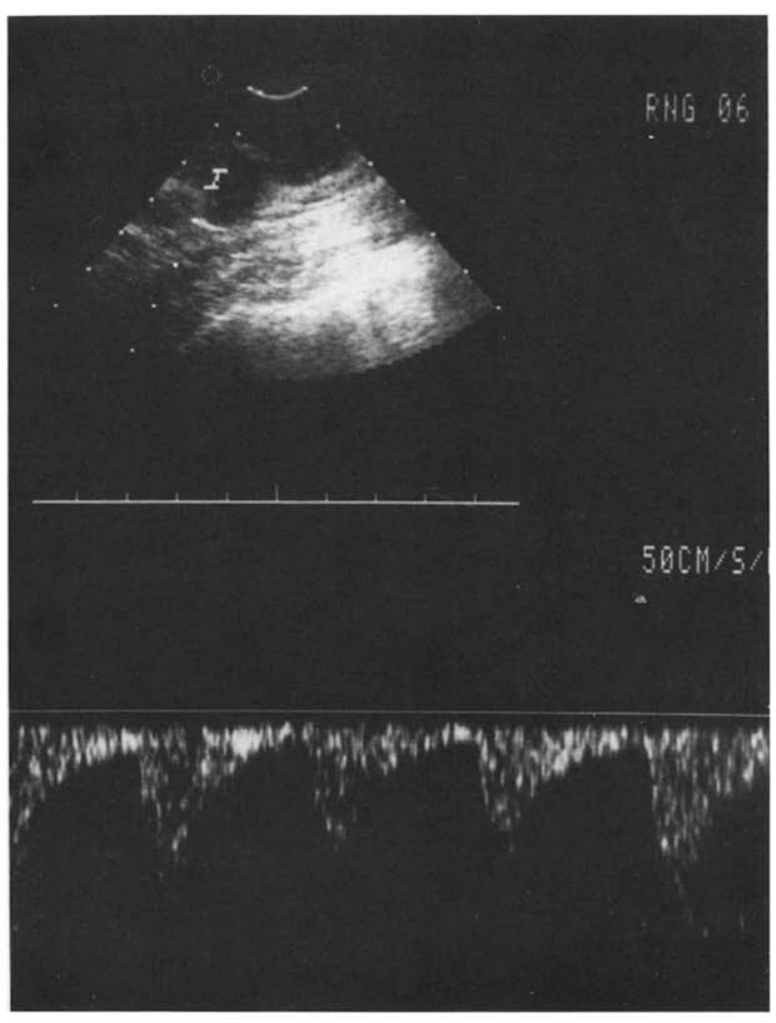

(b)

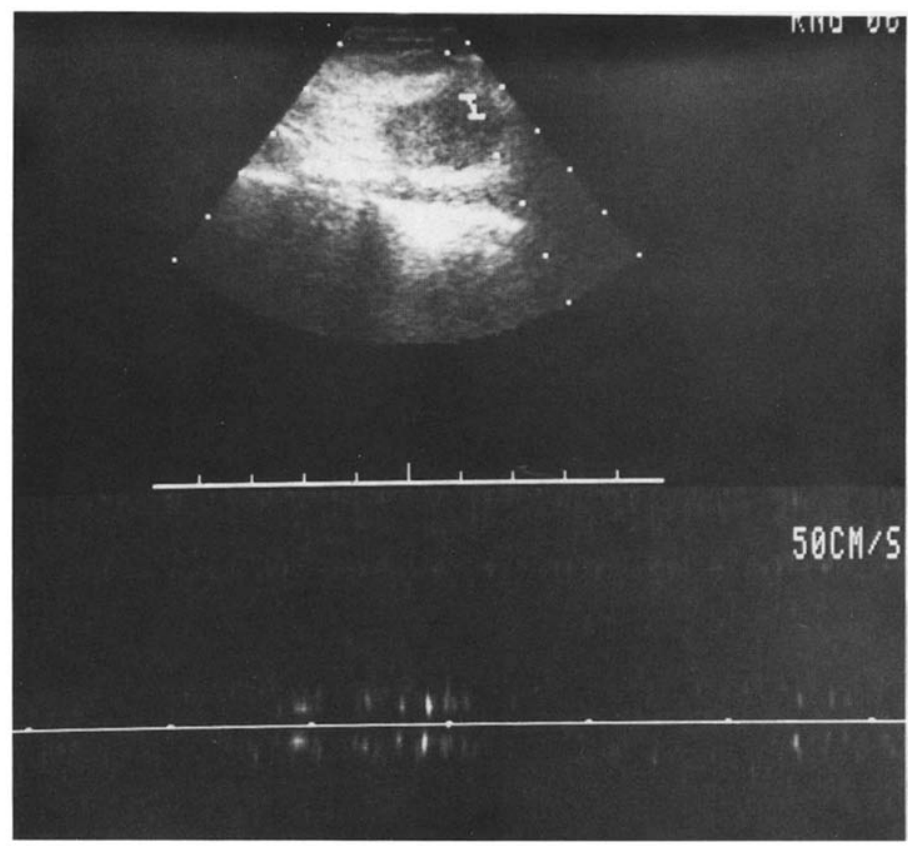

(c)

Fig. 1. (a) Mammography of the right breast in oblique view showed a dense lesion, (mass A, solid arrow) and a second isodense lobulated lesion (mass B, open arrow). (b) In mass B, that proved to be a carcinoma, a positive Doppler shift of 1.65/0.45 (S/D) $\mathrm{kHz}$ was found. (c) No signal was seen in mass A, a fibroadenoma. 
Table 3. Correlation between duplex ultrasound and axillary nodal metastasis.

\begin{tabular}{|c|c|c|}
\hline \multirow[b]{2}{*}{ Duplex ultrasound } & \multicolumn{2}{|c|}{ Histologic diagnosis } \\
\hline & $\begin{array}{c}\text { Patients without } \\
\text { nodes }\end{array}$ & $\begin{array}{l}\text { Patients with } \\
\text { positive nodes }\end{array}$ \\
\hline \multicolumn{3}{|l|}{ Malignancy with high } \\
\hline frequency shift $\geqslant 1 \mathrm{kHz}$ & 15 & 16 \\
\hline \multicolumn{3}{|l|}{ Malignancy without or } \\
\hline frequency shift $<1 \mathrm{kHz}$ & 19 & 3 \\
\hline
\end{tabular}

a carcinoma had a positive Doppler signal, while the 26 patients with a negative Doppler signal proved to have benign lesions.

The strength and ease of detection of a Doppler signal depends on the vascular bed. In our study there was no obvious correlation between tumor size and Doppler shift (a large tumor size may comprise a necrotic centre or considerable cystic components).

According to our results, a high frequency shift is not related to the presence of axillary nodal metastasis (Table 2). But when no positive Doppler signal was seen, only a small minority ( 3 of 22 patients) had positive nodes. In this context it is important to realize that duplex Doppler ultrasound is a highly operatordependent technique. It is possible that in the three above-mentioned patients with nodal metastasis, no high frequency shift is seen because of operator failure.

In our opinion only positive findings are reliable. Lesions with a high frequency shift are highly suspicious of malignancy. But a reasonable number of breast malignancies do not show a frequency shift, making further work-up in case of negative findings also necessary.

In conclusion, we must say that duplex Doppler ultrasound has a limited role in the differentiation of benign and malignant disease. However, a frequency shift of more than $1 \mathrm{kHz}$ indicates a high probability for malignancy, without predictive value for nodal involvement. A negative Doppler finding in a breast malignancy showed a high correlation with a negative axillary nodal status.

\section{REFERENCES}

Bohm-Velez, M.; Mendelson, E. B. Computed tomography, duplex Doppler ultrasound and magnetic resonance imaging in evaluating the breast. Semin. Ultrasound CT MR 10:171-176; 1989.

Burns, P. N.; Halliwell, M.; Wells, P. N. T. Ultrasonic Doppler studies of the breast. Ultrasound Med. Biol. 8:127-143; 1982.

Cole-Beuglet, C.; Soriano, R. Z; Kurtz, A. B.; Goldberg, B. B. Ultrasound analysis of 104 primary breast carcinomas classified according to histo-pathologic type. Radiology 147:191-196; 1983.

Dock, W.; Grabenwoeger, F.; Metz, V.; Eibenberger, K.; Farres, M. T. Tumor vascularization: Assessment with duplex sonography. Radiology 181:241-244; 1991.

Folkman, J.; Hanahan, D. Switch to the angiogenic phenotype during tumorigenesis. Princess Takamatsu Symp. 339-347; 1991.

Kuijpers, T. J. A.; Jaspers, R. Renal masses: Differential diagnosis with pulsed Doppler ultrasound. Radiology 170:59-60; 1989.

Ramos, I.; Taylor, K. W. J.; Kier, R.; et al. Tumor vascular signals in renal masses: Detection with Doppler ultrasound. Radiology 168:633-637; 1988.

Schoenberger, S. G.; Sutherland, C. M.; Robinson, A. E. Breast neoplasms: Duplex sonographic imaging as an adjunct in diagnosis. Radiology 168:665-668; 1988.

Taylor, K. J. W. Ultrasonic tissue characterization. Applied Radiology $45-50 ; 1987$.

Taylor, K. J. W.; Ramos, I.; Morse, S. S.; Fortune, K. L.; Hammers, L.; Taylor, C. R. Focal liver masses: Differential diagnosis with Doppler ultrasound. Radiology 164:643-647; 1987.

Taylor, K. J. W.; Ramos, I.; Carter, D.; Morse, S. S.; Snower, D.; Fortune, K. Correlation of Doppler US tumor signals with neovascular morphologic features. Radiology 166:57-62; 1988.

Taylor, K. J. W.; Holland, S. Doppler US part I: Basic principles, instrumentation and pitfalls. Radiology 174:297-307; 1990.

Weidner, N.; Folkman, J.; Pozza, F.; Bevilacqua, P.; Allred, E. N. Tumor angiogenesis: A new significant and independent prognostic indicator in early-stage breast carcinoma. J. Natl. Cancer Inst. 84(24): 1875-1887; 1992. 